\title{
Góndola, Enseñanza y Aprendizaje de las Ciencias
}

ENSINO POR INVESTIGAÇÃO: PERCEPÇÕES DE DOCENTES SOBRE SUAS PRÁTICAS INQUIRY-BASED TEACHING: TEACHERS PERCEPTIONS ABOUT ITS PRACTICES LA ENSEÑANZA POR INVESTIGACIÓN: PERCEPCIONES DE DOCENTES SOBRE SUS PRÁCTICAS

\author{
Tamires Bartazar Araújo* (i) , João Paulo Camargo de Lima**(i) y Marinez Meneghello Passos***
}

Cómo citar este artículo: Bartazar Araújo, T., Camargo de Lima, J.P. y Passos, M.M. (2020). Ensino por investigação: percepções docentes sobre suas práticas. Góndola, enseñanza y aprendizaje de las ciencias, 15(2), 370-383. DOI:

https://doi.org/10.14483/23464712.14834

\begin{abstract}
Resumo
Neste artigo trazemos os resultados de uma pesquisa que identificou as percepções de três professoras dos anos iniciais do Ensino Fundamental a respeito de suas práticas pedagógicas a partir do ensino por investigação, proposto a elas em uma situação de formação continuada. Os dados foram coletados por meio de um questionário e interpretados à luz de um instrumento denominado Matriz 3x3, o qual nos auxiliou na evidenciação dessas percepções. Assumindo os procedimentos da análise de conteúdo e as nove células da Matriz por categorias a priori, foi possível concluir que: a grande maioria das manifestações das professoras depoentes concentrou-se na dimensão epistêmica, naquilo que diz respeito ao ensino que pratica; em um destaque secundário, também relacionado à dimensão epistêmica tivemos os relatos sobre a aprendizagem dos alunos; com relação à dimensão pessoal, ou seja, seus gostos ou apreciações, só houve uma manifestação; por fim, quando observamos a dimensão social, encontramos cinco destaques, sendo quatro deles relativos à valorização do ensino praticado por elas e um deles focando a aprendizagem dos alunos. As reflexões giraram em torno da dimensão epistêmica, o que nos leva a ressaltar a necessidade de intensificação dos processos formativos continuados para que os professores possam refletir mais sobre os aspectos pessoais e sociais do ensino por investigação.
\end{abstract}

Palavras-chave: formação de professores; prática pedagógica; ensino de ciências; ensino por investigação.

Recebido: 30 de abril de 2019; aprovado: 23 de agosto de 2019

* Mestre em Ensino de Ciências Humanas, Sociais e da Natureza, Universidade Tecnológica Federal do Paraná (UTFPR), Campus Londrina. Docente da Escola Municipal Olavo Soares Barros no município de Cambé. Atua na Secretaria Municipal de Educação do Município de Londrina na coordenação de educação de Jovens e Adultos, egressa do programa de Pós-graduação em Ensino de Ciências Humanas, Sociais e da Natureza, UTFPR, Campus Londrina. Correio eletrônico: tamires.araujo23@prof.londrina.pr.gov.br

** Doutor em Física, Universidade Federal de São Carlos, Brasil. Docente do Departamento Acadêmico de Física da Universidade Tecnológica Federal do Paraná (UTFPR), Campus Londrina, e do programa de Pós-graduação em Ensino de Ciências Humanas, Sociais e da Natureza, UTFPR, Campus Londrina. Correio eletrônico: joaopaulo@utfpr.edu.br

*** Doutora em Educação para a Ciência, Universidade Estadual Paulista "Júlio de Mesquita Filho" (UNESP), Brasil. Docente sênior da Universidade Estadual de Londrina (UEL) e docente colaboradora da Universidade Estadual do Norte do Paraná (UENP), Câmpus Cornélio Procópio, Brasil. Correio eletrônico: marinezpassos@uel.br 


\begin{abstract}
This study sought to identify the perceptions of three teachers from the initial years of elementary education regarding their pedagogical practices of inquiry-based teaching, which was proposed to them in a situation of continuous formation. Data were collected through a questionnaire and interpreted from an instrument called 3x3 Matrix to ascertain their perceptions. Drawing from the results of content analysis and the nine cells of the Matrix by a priori categories, this study concluded that: majority of the manifestations of the teachers' speech concentrated on the epistemic dimension regarding the type of teaching they practiced; in a secondary highlight, they also related to the epistemic dimension regarding the students' learning; regarding the personal dimension (their tastes or appreciations), there was only one manifestation; and finally, regarding the social dimension, five highlights were identified, and four of them related to the valorization of the teaching practiced by the teachers and one focused on student learning. The reflections revolved around the epistemic dimension, which leads us to highlight the need for intensification of the continuing formative processes so that teachers can reflect more on the personal and social aspects of teaching by research.
\end{abstract}

Keywords: teacher education; teaching practice; science teaching; inquiry-based teaching.

\title{
Resumen
}

Presentamos los resultados de una investigación que identificó las percepciones de tres profesoras de cursos de básica primaria, acerca de sus prácticas pedagógicas a partir de la enseñanza por investigación, propuesto a ellas en una situación de formación continuada. Los datos fueron recolectados por medio de un cuestionario e interpretados a la luz de un instrumento denominado Matriz $3 \times 3$, el cual nos ayudó a organizar la evidencia de esas percepciones. Asumiendo los procedimientos del análisis de contenido y las nueve células de la Matriz por categorías a priori, fue posible concluir que: la gran mayoría de las manifestaciones de las profesoras participantes se concentró en la dimensión epistémica, en lo que se refiere a la enseñanza que practican; en segundo lugar, también relacionado con la dimensión epistémica encontramos los relatos sobre el aprendizaje de los alumnos; con respecto a la dimensión personal, es decir, sus gustos o apreciaciones solo hubo una manifestación; finalmente, cuando observamos la dimensión social, encontramos cinco ideas sobresalientes, siendo cuatro de ellas relativas a la valoración de la enseñanza practicada por las profesoras y una idea enfocada al aprendizaje de los alumnos. Las reflexiones giraron en torno a la dimensión epistémica, lo que nos lleva a resaltar la necesidad de intensificar los procesos formativos continuos para que los docentes puedan reflexionar más sobre los aspectos personales y sociales de la enseñanza mediante la investigación.

Palabras clave: formación de profesores; práctica pedagógica; enseñanza de ciencias; enseñanza por investigación. 


\section{Introdução}

O interesse das crianças pela Ciência começa com a curiosidade desde a mais tenra idade a partir da observação que realizam em seu cotidiano. Assim, aspectos como fascinação, motivação, iniciativa, entre outros, contribuem para a apropriação de conhecimentos durante as situações de ensino relativas a essa disciplina curricular (Arce, Silva, Varotto, 2011). Situações essas que vão ao encontro da função social e educacional da escola, no que diz respeito à disponibilização do conhecimento científico para os alunos desde os primeiros anos da escolarização.

Todavia, ao longo de seu percurso nos anos e anos de escolaridade, a curiosidade e o interesse investigativo dos alunos vão se perdendo, pois os mesmos vão se habituando a um mundo pronto e acabado, no qual há fragilidades na busca pelo conhecimento e no ensino dos conteúdos científicos, levando-os a concluir que quem faz Ciência são apenas os grandes cientistas (Arce, Silva, Varotto, 2011).

Por conseguinte, é necessário que os professores em suas aulas despertem e incentivem seus alunos para a aprendizagem e o acesso ao conhecimento científico, de modo que tenham a oportunidade de ampliar a apropriação de conceitos científicos, vivenciar a produção de pesquisas científicas, testar suas hipóteses e produzir ciência, a seu modo, é claro.

Diante dessas situações nos propusemos a investigar as percepções de três professoras dos anos iniciais do Ensino Fundamental a respeito de suas práticas pedagógicas a partir do ensino por investigação, proposto a elas durante um processo de formação continuada.

A fim de esclarecer como a pesquisa foi desenvolvida e as conclusões a que chegamos, estruturamos o artigo da seguinte forma: na sequência desta introdução inserimos uma seção em que descrevemos algumas considerações a respeito de formação de professores e o ensino por investigação; na continuidade apresentamos a Matriz $3 \times 3$, um instrumento que nos auxiliou a organizar os dados e cujas células foram assumidas por categorias a priori; nas seções subsequentes temos os procedimentos metodológicos, a discussão dos dados e as considerações conclusivas.

\section{Formação de professores e o ensino por investigação nas aulas de Ciências}

Ser professor, isto é, formar-se professor é uma tarefa cada vez mais complexa. Carvalho, Gil-Pérez (2011) refletem acerca das visões simplificadas sobre a formação dos professores de Ciências e destacam a necessidade de uma formação sistematizada para garantir uma docência de qualidade, tarefa difícil, em função das limitações dos cursos e, ainda, do tempo limitado para a formação inicial.

Entende-se que a formação do professor não se esgota na formação inicial, pois ela constitui-se em um processo contínuo, no qual pode alcançar êxitos nos cursos de formação continuada. Cunha, Krasilchik (2000) apontam alguns aspectos que precisam ser considerados nos cursos de formação continuada, como a participação voluntária dos professores, material de apoio e integração conteúdo e metodologia.

A necessidade de formação permanente ou contínua também está articulada com as fragilidades da formação inicial. Nessa perspectiva, Carvalho, Gil-Pérez (2011) elencam que a necessidade da formação contínua vai além da superação dessas fragilidades, visto que muitas situações tratadas nesse momento formativo não teriam fundamentos até que surgissem subsídios da prática do professor. Desse modo, os mesmos autores consideram que a amplitude da formação inicial visa suprir as exigências da formação docente, porém aumentaria consideravelmente a duração do curso inicial ou traria uma abordagem superficial ao tentar ampliar a dimensão da complexidade da prática da docência. Ainda, os autores ressaltam que uma formação docente efetiva pressupõe a participação continuada em grupos de trabalho desenvolvendo pesquisas/ação. 
Por outro lado, pesquisadores tem apontado críticas a respeito da formação continuada de professores, não quanto à sua finalidade de estar a serviço do aperfeiçoamento contínuo da prática profissional dos docentes, mas sim quanto aos poucos efetivos resultados sobre as práticas profissionais dos professores, e as mudanças nas práticas e concepções acerca do ensino e da aprendizagem em sala de aula (Galindo, Inforsato, 2016). As críticas apontadas são no sentido de um repensar e um refazer dos processos de formação continuada de professores, apontando inclusive mudanças na lógica formativa a fim de realizar uma transição do discurso promissor à ações e práticas efetivas de mudanças na realidade da formação docente (Galindo, Inforsato, 2016; Mizukami et al., 2006).

Dentro desses pressupostos, faz-se pertinente que o profissional da educação busque sua formação continuada de maneira que alcance condições de promover interações entre os sujeitos da aprendizagem e os conhecimentos científicos, para que se favoreçam a apropriação desses conhecimentos pelos estudantes, conforme apontam Silva, Bastos (2012).

Carvalho, Gil-Pérez (2011) argumentam que cabe ao professor indagar as visões de Ciências que são trabalhadas de forma repetitiva, dogmática e acrítica, para romper com as abordagens simplistas de senso comum. Todavia, os autores ressaltam que é necessário que haja um trabalho coletivo em todo processo de ensino e de aprendizagem, desde a preparação das aulas até o momento da avaliação, que vise à aquisição do conhecimento em Ciências. Em suma, trata-se de conduzir a tarefa docente como um trabalho coletivo de inovação, pesquisa e formação permanente.

Baccon (2005) acrescenta que, mesmo depois de sua bagagem de formação, "o cotidiano escola" aponta que falta certo saber ao professor, um saber que não se ensina nas universidades. Todavia, esse saber é adquirido e elaborado a partir da prática do professor e muita reflexão. Assim, a formação docente não se completa com a aquisição de um diploma, essa é a etapa inicial para que o professor elabore sua identidade profissional.
Moita (1995) esclarece que a identidade profissional é construída em uma dimensão que permeia a vida profissional desde a escolha pela profissão até a reforma, isto é, compreende-se o tempo de formação inicial e os "diversos espaços instituições" em que a profissão acontece. Além disso, é construída sobre os saberes científicos, pedagógicos, éticos, da experiência e das decisões tomadas.

Destaca-se, também, que a identidade vai sendo elaborada a partir das experiências, da história pessoal e no coletivo social. Logo, a identidade profissional necessita de um espaço de formação para se estruturar, uma vez que experiências e vivências internas e externas às universidades contribuem para a construção de identidade docente (Pimenta, Lima, 2004). Desse modo:

Uma identidade profissional se constrói, pois, a partir da significação social da profissão; da revisão constante dos significados sociais da profissão; da revisão das tradições. Mas também da reafirmação de práticas consagradas culturalmente e que permanecem significativas. Práticas que resistem a inovação porque prenhes de saberes válidos às necessidades da realidade [...]. (Pimenta, 2012 p.20)

Consequentemente, problematiza-se: quais são os saberes que fazem parte da ação docente? Tardif (2007) esclarece que o saber docente é formado pelo amálgama dos saberes oriundos da formação profissional, disciplinar, curricular e de suas experiências e detalha que disciplinares são os "saberes sociais", curriculares são aqueles que "correspondem aos discursos, objetivos, conteúdos e métodos" e os relativos às experiências são os "saberes baseados em seu trabalho cotidiano proveniente do conhecimento de seu meio" (Tardif, 2007 p. 36).

Essas experiências vividas durante o trabalho cotidiano do professor elaboram o alicerce da prática e da competência profissional, pois a experiência é condição para que o mesmo adquira e produza seus próprios saberes profissionais (Tardif, 2007). O que nos leva a considerar que a sala de aula é um 
espaço privilegiado na construção dos saberes docentes e na construção da identidade do professor.

O professor precisa ser capaz de atuar na docência, na gestão de processos educacionais e na construção e propagação do conhecimento científico. Dessa maneira, a formação docente precisa articular os estudos teóricos e de atividades práticas contemplando o cotidiano escolar e os processos de investigação educacional (Silva, Bastos, 2012).

Posto que a formação continuada tenha que ser considerada de extrema importância para profissionais da educação e refere-se a um processo permanente de desenvolvimento profissional que tem ser assegurado a todos (Brasil, 1999), ressalta-se que é possível aprimorar e realizar novas práticas de ensino por meio da reflexão, da transformação e recondução da ação docente, viabilizada por essa formação contínua.

Nesse sentido destaca-se, dentre as tendências do ensino de Ciências, o ensino por investigação como uma oportunidade de estratégia a ser desenvolvido pelo professor nas aulas de Ciências, bem como uma possibilidade de o professor recriar suas práticas a partir de uma revisão sobre sua ação em sala de aula.

Sabe-se que o ensino por investigação foi conhecido como "inquiry" e na literatura assumiu várias definições, como: ensino por descoberta; aprendizagem por projetos; questionamentos; resolução de problemas, sequências investigativas, entre outras (Zômpero, Laburú, 2011). Apesar dessas divergências nominais, há uma convergência quando a literatura descreve o ambiente e as ações nele realizadas, destacando a necessidade da criação de um ambiente investigativo em salas de aula de Ciências, de tal forma que os alunos possam ser ensinados no processo do trabalho científico (Carvalho, 2013) que propicie o desenvolvimento de atividades investigativas.

Campos, Nigro (1999) afirmam que não se deve requerer nos anos iniciais do Ensino Fundamental, que as crianças sigam o rigor do método científico, entretanto, propõe-se o desenvolver de algumas atividades que viabilizem o primeiro passo para a observação dos fatos, o levantamento de problemas, de hipóteses e a elaboração de palpites de seus próprios questionamentos. Outro aspecto importante é que as atividades investigativas precisam apresentar algumas características, como:

[...] o engajamento dos alunos para realizar as atividades; a emissão de hipóteses, nas quais é possível a identificação dos conhecimentos prévios dos mesmos; a busca por informações, tanto por meio dos experimentos, como na bibliografia que possa ser consultada pelos alunos para ajudá-los na resolução do problema proposto na atividade; a comunicação dos estudos feitos pelos alunos para os demais colegas de sala, refletindo, assim, um momento de grande importância na comunicação do conhecimento, tal como ocorre na Ciência, para que o aluno possa compreender, além do conteúdo, também a natureza do conhecimento científico que está sendo desenvolvido por meio desta metodologia de ensino. (Zômpero, Laburú, 2011 p.79)

Nesse contexto, o ensino por investigação tem por finalidade "levar os alunos a pensar, debater, justificar suas ideias e aplicar seus conhecimentos em situações novas, usando os conhecimentos teóricos" (Azevedo, 2006 p. 20). Desse modo, é necessário que na sala de aula o aluno tenha contato com atividades enriquecedoras, que despertem a reflexão sobre o problema ou questão a ser investigada, propiciando a elaboração e a sistematização dos conhecimentos.

Nigro (2011) propõe uma discussão interessante ao refletir como despertar o processo investigativo em crianças. Assim, o autor esclarece que o professor tem que criar condições para que os estudantes se engajem em processos investigativos, ou seja, criar condições para que façam Ciências, uma vez que essa construção nos possibilita sugerir diversas situações, nas quais o aluno pode se portar como cientista, isto é, adotar procedimentos que aludem aos procedimentos desses profissionais e vislumbrem como o conhecimento científico é produzido (Nigro, 2011). 
Observa-se que o interesse pelo tema ensino por investigação no Brasil é cada vez mais crescente entre pesquisadores e professores da área de Ciências. Porém, o número de artigos publicados nesta área ainda é pouco significativo (Sá, 2009). Considera-se que há um longo caminho a ser percorrido sobre o ensino por investigação no país, o que amplia cada vez mais a necessidade de cursos de formação continuada direcionado ao ensino de Ciências. Ensejos esses que nos conduziram à realização desta investigação.

Como anunciado anteriormente, trazemos agora alguns esclarecimentos a respeito da Matriz $3 \times 3$, um instrumento que nos auxiliou a organizar e interpretar os dados coletados durante a pesquisa e a identificar nas respostas dos depoentes suas percepções a respeito de sua prática quando revisitada pelo que haviam aprendido durante a formação continuada sobre ensino por investigação.

\section{Gestão das relações na sala de aula: a Matriz 3x3}

A ação docente em sala de aula inclui as relações que acontecem nesse ambiente e sua gestão. Nesse sentido, a relação com o saber contempla três dimensões: a epistêmica, a pessoal e a social (Charlot, 2000), adaptado por Arruda, Lima, Passos (2011), e que consideram que, para o professor, o saber é o conteúdo disciplinar, mas é também um saber acerca do ensinar e um saber sobre o aprender.

Arruda, Lima, Passos (2011) esclarecem, ainda, que a relação epistêmica concebe o saber como objeto do mundo que pode ser apropriado e compreendido pelo sujeito; a relação pessoal refere-se ao saber como objeto de desejo e interesse do sujeito, o qual revela sua identidade com o saber; por fim, a relação social compreende o saber com o objeto social, caracterizado por valores atribuídos pela sociedade e por influências das expectativas dos outros sobre ele. Essas três relações foram representadas por seus idealizadores nas linhas da Matriz $3 \times 3$, descrita no Quadro 1.

Retomemos agora a última frase do primeiro parágrafo desta seção, em que temos destacado o conteúdo, o ensinar e o aprender e que para Arruda, Lima, Passos (2011) possuem estreita ligação com a estrutura triangular, representada na Figura 1, constituída por um saber (S) que para nós seria o conteúdo disciplinar, um professor $(\mathrm{P})$ que pratica seu ensino, um grupo de estudantes (E) envolvido com seu aprendizado. Tal estrutura ficou conhecida como "triângulo didático ou triângulo pedagógico" (Gauthier et al., 2006 p. 172, nota de rodapé), tendo sido utilizada por diversos autores, dentre eles Chevallard (2005) e Houssaye (2007). Esses três vértices do triângulo foram alocados nas colunas da Matriz 3×3 (ver Quadro 1).

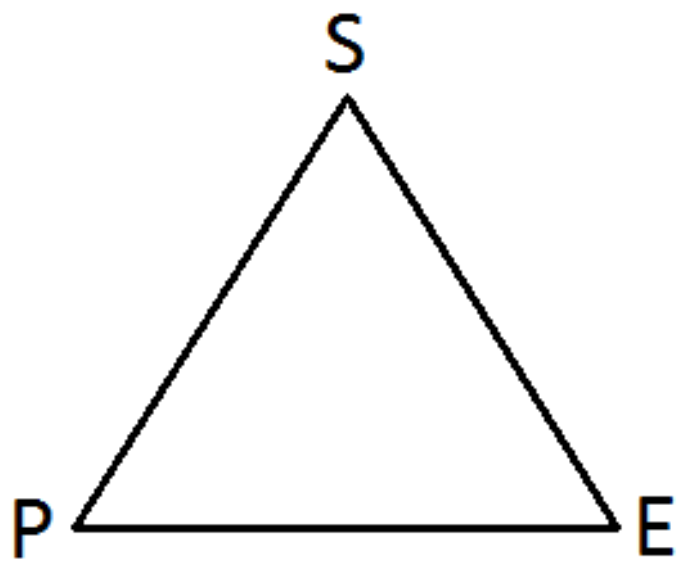

Figura 1. Triângulo didático-pedagógico. Fonte: Arruda e Passos (2017 p.100).

Cabem, ainda, alguns esclarecimentos a respeito deste triângulo e das interpretações que ele nos possibilita. Como podemos observar, ele é formado por três segmentos que foram assumidos como as relações entre professor e o saber (P-S), entre o professor e o estudante (P-E) e entre o estudante e o saber (E-S). Segundo Arruda, Lima e Passos (2011), a gestão do segmento P-S designa-se à gestão das relações do professor com o conteúdo disciplinar, P-E diz respeito à gestão das relações do professor com o ensino e E-S à gestão das relações do professor com a aprendizagem, o que nos levou a assumir esses modelos triangular e matricial para o desenvolvimento de nossa pesquisa, pois ajuda-nos a sistematizar as relações com o saber (para nós Ciências e ensino por investigação) no contexto de sala de aula. 
Com base no exposto, Arruda, Lima, Passos (2011) propuseram um instrumento de análise das relações com o saber docente denominado Matriz $3 \times 3$, recentemente renomeado "Matriz do Professor" em Arruda, Passos (2017), com a finalidade de investigar os vários aspectos da ação docente.

A seguir trazemos uma descrição adaptada de Arruda, Lima, Passos (2011) de cada uma dessas células especificando com mais detalhes os setores da Matriz $3 \times 3$, organizando a apresentação linha a linha, ou seja, Setores 1A, 2A, 3A; seguidos dos Setores 1B; 2B, 3B; e finalizando com os Setores 1C; 2C, 3C.

Setor $1 \mathrm{~A}$ - nesta célula delimitada pela dimensão epistêmica e pelo conteúdo considera-se as formas com que o professor se apropria desse conteúdo e procura compreendê-lo em profundidade, além disso, dá-se atenção aos objetos e aos locais em que esse conteúdo pode ser acessado (livros, revistas, sítios da internet, bibliotecas, entre outros); Setor 2A - tem-se aqui a confluência da dimensão epistêmica, pois nos mantemos na primeira linha da Matriz $3 \times 3$, e a relação que o professor estabelece com o ensino que pratica, neste caso, dando voz às percepções e reflexões que o professor realiza sobre sua formação para o magistério e suas atividades docentes, incluindo a busca por compreender esses processos, avaliando-os e procurando melhorá-los; relacionando-os com os materiais instrucionais, experimentos e instrumentos disponíveis e de que possa fazer uso; e, por fim, as habilidades que possui para planejar seus objetivos, os conteúdos a serem expostos, as atividades a serem realizadas, a elaboração de ava-

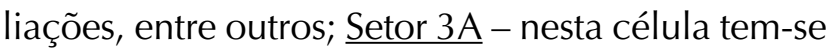
a relação epistêmica integrada à aprendizagem dos estudantes, aqui é considerada a compreensão que o professor possui a respeito das formas com que o aluno se mobiliza para aprender, percebendo e refletindo sobre as relações estabelecidas pelos alunos com o conteúdo, as ideias prévias que possuem sobre os assuntos em pauta e as dificuldades apresentadas para o desenvolvimento da aprendizagem, entre outros fatores relativos ao aprender desses estudantes.

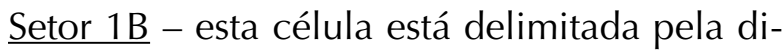
mensão pessoal, pois nos deslocamos para a segunda linha da Matriz $3 \times 3$, e pelo conteúdo, neste momento releva-se o efeito do sentido do conteúdo que o professor estabelece para si, levando-o à determinação de sua identidade profissional; destacando o quanto esse docente gosta e se envolve com esse conteúdo e os assuntos adjacentes a ele; além disso, consideram-se, neste setor, as manifestações pertinentes à sua autoavaliação para com a compreensão

Quadro 1. Matriz 3×3.

\begin{tabular}{|c|c|c|c|}
\hline $\begin{array}{l}\text { Novas tarefas do professor } \\
\begin{array}{l}\text { Relações com } \\
\text { o saber }\end{array}\end{array}$ & $\begin{array}{c}1 \\
\begin{array}{c}\text { Gestão do segmento P-S } \\
\text { (conteúdo) }\end{array}\end{array}$ & $\begin{array}{c}2 \\
\begin{array}{c}\text { Gestão do segmento P-E } \\
(\text { ensino })\end{array}\end{array}$ & $\begin{array}{c}3 \\
\begin{array}{l}\text { Gestão do segmento E-S } \\
\text { (aprendizagem) }\end{array}\end{array}$ \\
\hline $\begin{array}{c}\text { A } \\
\text { Epistêmica }\end{array}$ & $\begin{array}{c}\text { Setor } 1 \mathrm{~A} \\
\text { Diz respeito ao conteúdo } \\
\text { enquanto objeto a ser } \\
\text { compreendido pelo } \\
\text { professor. }\end{array}$ & $\begin{array}{l}\text { Setor } 2 \mathrm{~A} \\
\text { Diz respeito ao ensino } \\
\text { enquanto atividade a } \\
\text { ser compreendida pelo } \\
\text { professor. }\end{array}$ & $\begin{array}{c}\text { Setor } 3 \mathrm{~A} \\
\text { Diz respeito à } \\
\text { aprendizagem } \\
\text { enquanto atividade a } \\
\text { ser compreendida pelo } \\
\text { professor. }\end{array}$ \\
\hline $\begin{array}{c}\text { B } \\
\text { Pessoal }\end{array}$ & $\begin{array}{l}\text { Setor } 1 \mathrm{~B} \\
\text { Diz respeito ao conteúdo } \\
\text { enquanto objeto pessoal. }\end{array}$ & $\begin{array}{l}\text { Setor } 2 \mathrm{~B} \\
\text { Diz respeito a o ensino } \\
\text { enquanto atividade } \\
\text { pessoal. }\end{array}$ & $\begin{array}{l}\underline{\text { Setor } 3 \mathrm{~B}} \\
\text { Diz respeito à } \\
\text { aprendizagem enquanto } \\
\text { atividade pessoal. }\end{array}$ \\
\hline $\begin{array}{c}\text { C } \\
\text { Social }\end{array}$ & $\begin{array}{l}\frac{\text { Setor } 1 \mathrm{C}}{\text { Diz respeito ao conteúdo }} \\
\text { enquanto objeto social. }\end{array}$ & $\begin{array}{c}\underline{\text { Setor } 2 \mathrm{C}} \\
\text { Diz respeito ao ensino } \\
\text { enquanto atividade social. }\end{array}$ & $\begin{array}{c}\text { Setor } 3 \mathrm{C} \\
\text { Diz respeito à } \\
\text { aprendizagem enquanto } \\
\text { atividade social. }\end{array}$ \\
\hline
\end{tabular}

Fonte: Arruda, Lima e Passos (2011 p.147). 
do conteúdo em questão; Setor 2B - ocorre aqui a confluência da dimensão pessoal e a relação que o professor estabelece com o ensino que pratica, considerando como ele se autoavalia como docente; a forma como ele transpõem suas inseguranças didático-pedagógicas; ao sentido pessoal que ele atribui ao ensino que pratica e como isso contribui com a elaboração de sua identidade docente; destaca os seus gostos pelo ensinar; a constituição do seu estilo docente e as regras que ele próprio estabeleceu para chegar a esse estilo; o balizamento de suas responsabilidade, entre outros indicativos pessoais; $\underline{\text { Setor }}$ $\underline{3 \mathrm{~B}}$ - nesta célula tem-se a relação pessoal vinculada à aprendizagem dos estudantes, o quanto esse vínculo se integra à sua identidade como professor e o sentido que adquire para ele; a problemática gerada por aquilo que o responsabiliza diante do estímulo do interesse, do envolvimento e da motivação dos alunos em sala de aula; sua própria capacidade de estabelecer e/ou gerenciar a relação dos alunos com o conteúdo, entre outros destaques.

Setor 1C - neste momento sobressai os conteúdos escolares e a valoração deles por meio das manifestações sociais em uma sociedade de que o professor participa entre elas, a comunidade de educadores com quem ele está integrado, a comunidade pertencente aos eventos esporádicos de que possa vir a fazer parte ou a relação que estabelece com essas pessoas detentoras desses conhecimentos, sempre procurando o aperfeiçoamento desse convívio; Setor 2C - nesta célula aloca-se o ensino praticado pelo professor enquanto atividade social, enfatizando as dificuldades e as inseguranças inerentes a esse processo que está relacionada à aceitação e validação de outros, entre eles alunos, pais, professores, administradores escolares; suas habilidades em gerenciar e ensinar os alunos em sala de aula; os "[...] esforços que ele faz para conseguir apoio dos demais agentes sociais, cujas opiniões e avaliações afetam sua segurança, posição e sua autoridade enquanto professor, entre outros" (Arruda, Lima, Passos, 2011 p. 148). Setor $3 \mathrm{C}$ - tem-se, por fim, nesta última célula em descrição, o destaque à aprendizagem e sua valoração social, considerando a sala de aula como um ambiente propício ao desenvolvimento dessas interações que promovem a aprendizagem dos alunos e que possibilita o gerenciamento de atividades e propostas de trabalhos em grupo.

Após esses esclarecimentos a respeito da Matriz $3 \times 3$ (agora renomeada para Matriz do Professor) e algumas explicações sobre sua origem e o uso que faremos dela, trazemos diversos detalhes relativos à situação investigada e aos procedimentos metodológicos em que nos pautamos.

\section{Procedimentos metodológicos: alguns destaques}

A investigação que desenvolvemos configura-se por uma pesquisa qualitativa que se desenvolveu da observação das atividades do grupo estudado e da coleta de dados por meio de questionários, que segundo Gil (2007) consiste em um conjunto de questões que são respondidas por escrito pelos sujeitos da pesquisa.

No nosso caso, as questões respondidas pelas professoras foram as seguintes:

1. O que é ensino por investigação para você? Faça um relato de suas impressões a respeito do tema.

2. Em sua opinião, o ensino por investigação é importante? Por quê? Exemplifique.

3. Você utiliza ou utilizou práticas investigativas em suas aulas de Ciências? Quais? Faça uma breve descrição dessas práticas.

4. Em sua visão, como as práticas investigativas refletiram em seu trabalho em sala de aula?

A situação de formação continuada em que os dados foram coletados deu-se em um município do Norte do Paraná. Do processo formativo, participaram professores pedagogos que desenvolviam atividades investigativas com seus alunos de quinto ano dos anos iniciais do Ensino Fundamental. O levantamento para identificá-los foi realizado antecipadamente e o convite para a participação das atividades formativas foi entregue a todos, todavia nem todos tiveram disponibilidade para participar. 
A primeira etapa da proposta (cadastrada no município como um Projeto intitulado Iniciação Científica) consistiu em uma formação para coordenadores pedagógicos, diretores e alguns professores, com duração de quatro horas, visando a estruturação das etapas das pesquisas e atividades que foram desenvolvidos pelos alunos, pois a intenção primária do projeto era 'levar uma proposta de Iniciação Científica aos estudantes'. Todavia, para que isso acontecesse, elaboramos uma pauta focada na formação dos professores dessas escolas municipais, a qual foi ministrada por uma professora da rede estadual de ensino, graduada em Ciências Biológicas com Mestrado em Ensino de Ciências. Os tópicos principais dessa formação diziam respeito ao 'ensino por investigação: proposições e desafios' e 'etapas para o desenvolvimento de atividades investigativas'.

Na segunda etapa os coordenadores repassaram as orientações recebidas no curso de formação para os professores que não puderam estar presentes na formação. Frisa-se que no decorrer do projeto, quando solicitado, os professores receberam orientação e apoio da assessoria pedagógica do município.

Em seguida, os professores planejaram e desenvolveram atividades investigativas, em que os alunos definiram questões de pesquisas, confeccionaram um "Diário de Bordo", que foi um caderno ou pasta, no qual eles próprios registravam o que haviam pensado e realizado. Após testarem hipóteses e concluírem seus trabalhos, as atividades de pesquisa foram impressas em banners que culminarão na apresentação da "I Mostra de Iniciação Científica" do referido município.

Considerando que diversas professoras envolveram-se com esse processo, desenvolvendo as atividades investigativas com seus alunos, convidamos inúmeras delas para responder a um questionário - três aceitaram - e suas respostas constituem os dados que trazemos neste artigo. O questionário foi encaminhado para o e-mail das professoras e, após o recebimento, as docentes foram nomeadas como P1, P2 e P3, conforme a sequência do retorno, a fim de preservar suas identidades.
O questionário foi encaminhado às professoras no final do mês de agosto de 2016, pois as atividades investigativas já haviam sido finalizadas e professores e alunos preparavam-se para a "Il Mostra de Iniciação Científica" que aconteceria no final do mês de setembro. Elas levaram cerca de 10 dias para devolverem seus relatos, que em seguida foram submetidos aos procedimentos da análise de conteúdo proposto por Bardin (2011). Assumindo que possuíamos categorias preestabelecidas, passamos a interpretar as respostas segundo esses parâmetros, realizando codificações nos fragmentos analisados e agrupando-os.

Com base em Bardin (2011), para realizar esse movimento analítico centramos nossas atenções nas unidades de contexto, ou seja, procuramos evidenciar qual era a unidade de contexto em que o fragmento daquele depoimento poderia ser alocado, pois, segundo a análise de conteúdo, geralmente, pretende-se construir um discurso coerente e dotado de alguma unidade argumentativa a partir da seleção/interpretação de falas que se acomodam e se relacionam com a fundamentação adotada.

Para essas identificações, contextualizações e acomodações foram realizados três movimentos: primeiramente, os trechos das respostas de P1, P2 e P3 passaram por um processo de identificação, em que nos perguntávamos se aquela unidade tinha relação com algo epistêmico, pessoal ou social; após esse movimento de alocação passamos a considerar se o contexto relatado dizia respeito ao conteúdo, ao ensino ou à aprendizagem; por fim, de posse dessa distribuição em termos dos descritores da Matriz $3 \times 3$, passamos a analisar o que aquele perfil delineado pelas células da Matriz revelava sobre as percepções docentes a partir de uma experiência com o ensino por investigação. Na seção seguinte trazemos diversos elementos que elucidam as identificações, contextualizações e acomodações. Justificamos que não apresentamos os dados em sua completude, pois em um artigo torna-se longo e exaustivo realizar tal proposição. Contudo, as considerações conclusivas ocorreram em função de todos os dados que possuímos. 


\section{Apresentação e discussão dos dados}

Esta seção foi estruturada da seguinte forma: questionário editado retornado pelo professor, considerando somente os fragmentos numerados, em sequência, para as três professoras, e relacionados às unidades de contexto vinculadas às células da Matriz $3 \times 3$; alocação dessas numerações/codificações em uma Matriz, para cada uma das professoras, independentemente; discussão do que isso representa diante da questão que procuramos responder: Quais são as percepções das professoras investigadas a respeito de suas práticas pedagógicas a partir do ensino por investigação?

Registros de P1 organizado por questões, isto é, cada conjunto de frases é o retorno a cada uma das quatro questões solicitadas para que respondessem.

“Ensino' por investigação para mim é o ensino que se inicia por questionamentos [1]. A aprendizagem nessa perspectiva ocorre da iniciativa do próprio aluno que tem o papel principal no processo de ensino-aprendizagem [2]".

"É importante [3], pois proporciona aos alunos a descoberta da capacidade que os mesmos têm na autorregulação da sua aprendizagem [4], pois os mesmos passam a relacionar os conhecimentos ensinados com acontecimentos do dia a dia [5], desse modo os alunos passam a ser protagonistas do ensino [6]".

1. As falas sofreram pequenas correções para a forma culta, sem que o sentido fosse modificado ou alterado.
"Tento ao máximo utilizar essa prática em minhas aulas [7], mas muitas vezes o tempo não permite que os alunos tragam seus questionamentos para a sala [8]".

"O trabalho pedagógico passa a ser bem mais dinâmico [9], formulado através de questionamentos, investigações e descobertas [10]. Desse modo a atuação do aluno é efetiva [11]".

Observem como esses excertos foram alocados na Matriz de P1 da Quadro 2.

Nota-se que as respostas de $\mathrm{P} 1$ dizem respeito predominantemente a uma percepção epistêmica com preocupações relativas ao ensino que ela pratica e à aprendizagem (linha A). Ficou perceptível que $\mathrm{P} 1$ realizava reflexões constantes da sua prática docente e sobre a aprendizagem de seus alunos. Todavia, reconhece a importância do desenvolvimento do ensino por investigação, atribuindo-lhe valor social em sua resposta [3].

Movimento semelhante pode ser observado nas acomodações das respostas de P2 descritas a seguir.

"É a criança procurar e investigar sobre determinado tema [12], fazer uma pesquisa para então compreender o assunto [13]".

"Sem dúvida sim, muito importante [14], pois é a partir deste que os alunos começam a ter maturidade para procurar e desenvolver um trabalho de pesquisa [15]".

"Até agora não tinha usado este método, mas depois da iniciação científica, acredito que vou desenvolver [16]".

Quadro 2. Representação das respostas de P1 na Matriz 3×3.

\begin{tabular}{|c|c|c|c|}
\hline $\begin{array}{c}\text { Novas tarefas do professor } \\
\text { Relações com } \\
\text { o saber }\end{array}$ & $\begin{array}{c}\mathbf{1} \\
\text { Gestão do segmento P-S } \\
\text { (conteúdo) }\end{array}$ & $\begin{array}{c}\mathbf{2} \\
\text { Gestão do segmento P-E } \\
\text { (ensino) }\end{array}$ & $\begin{array}{c}\mathbf{3} \\
\text { Gestão do segmento E-S } \\
\text { (aprendizagem) }\end{array}$ \\
\hline $\begin{array}{c}\text { A } \\
\text { Epistêmica }\end{array}$ & $1,6,7,8,9,10$ & $2,4,5,11$ \\
\hline $\begin{array}{c}\text { B } \\
\text { Pessoal }\end{array}$ & $\begin{array}{l}\text { C } \\
\text { Social }\end{array}$ & 3 & \\
\hline
\end{tabular}

Fonte: os autores. 
"De forma bem eficaz [17], pois podemos partir de algo que já foi visto e que eles já conseguem acrescentar, tendo um conhecimento prévio [18]".

Seguem as alocações na Quadro 3.

Verifica-se que, coincidentemente, as respostas de P2, em sua maioria, ficaram alocadas na primeira linha, indicando uma relação epistêmica com o ensino (4 excertos) e com a aprendizagem (2 excertos). Entretanto, percebe-se que P2 foi sucinta e objetiva em suas respostas e destaca-se que sua reflexão foi maior acerca de sua prática docente [12] e [18]. O que nos conduz à evidência de suas reflexões em torno de sua prática, quando menciona sobre o interesse em desenvolver outras vezes atividades investigativas com seus alunos [16] e admite o valor atribuído ao ensino por investigação.

Para P3 estruturamos a apresentação de suas respostas e a Matriz da mesma forma que com as duas professoras anteriores.

"Proporcionar aos alunos um momento de busca e investigação a um determinado conhecimento (conteúdo) [19]. No início senti um receio do trabalho [20] por ser o meu primeiro, no decorrer já estava conformada e confiante [21], no final houve diversos contratempos [22], mas tudo acabou bem [23]".

"Sim, porque leva o aluno a buscar conhecimento sobre assuntos relevantes [24] e os preparar para os próximos anos [25]".
"Antes do projeto Iniciação Científica não [26], mas agora parcialmente sim [27], estamos trabalhando os tecidos com os $4^{\circ}$ anos [28] e pedi que eles pesquisassem sobre o mesmo [29], e em grupos apresentassem para a sala a função do tema proposto [30], na teoria (por extenso) e em imagens (desenhos e imagem de alto-relevo) [31]".

"Contribui para trabalhar os conteúdos [32], os alunos adquiriram conhecimento sobre o tema proposto [33] e demonstraram satisfeitos com o trabalho [34]".

A distribuição dos excertos na Matriz de P3 pode ser observada na sequência (Quadro 4).

Percebe-se que, apesar de as respostas terem se concentrado na linha destinada às relações epistêmicas, P3 foi a única professora que trouxe assinalamentos relativos às três gestões: conteúdo, ensino e aprendizagem. Além disso, tivemos alocações em outras células, não povoadas, pelas manifestações de P1 e P2, como pode ser observado agilmente na terceira coluna da Matriz em que todas as células possuem pelo menos um excerto. Cremos que essas diferenciações se devem ao fato de que $\mathrm{P} 3$ procurou se manifestar por meio de exemplos relacionados à sua prática em sala de aula, ou seja, exemplos que destacam o ensino que ela pratica.

Identifica-se que as reflexões realizadas pela professora P3 alocadas nas colunas 2 e 3 da Matriz ficaram quase que equiparadas, inferindo-se que a preocupação de P3 com suas práticas de ensino, seja epistêmica, pessoal ou social, assemelha-se com sua preocupação com a aprendizagem dos alunos.

Quadro 3. Representação das respostas de P2 na Matriz 3x3.

\begin{tabular}{|c|c|c|c|}
\hline $\begin{array}{c}\text { Novas tarefas do professor } \\
\text { Relações com } \\
\text { o saber }\end{array}$ & $\begin{array}{c}\mathbf{1} \\
\text { Gestão do segmento P-S } \\
\text { (conteúdo) }\end{array}$ & $\begin{array}{c}\mathbf{2} \\
\text { Gestão do segmento P-E-E } \\
\text { (ensino) }\end{array}$ & $\begin{array}{c}\mathbf{3} \\
\text { Gestão do segmento E-S } \\
\text { (aprendizagem) }\end{array}$ \\
\hline $\begin{array}{c}\text { A } \\
\text { Epistêmica }\end{array}$ & $12,16,17,18$ & 13,15 \\
\hline $\begin{array}{c}\text { B } \\
\text { Pessoal }\end{array}$ & $\begin{array}{c}\text { C } \\
\text { Social }\end{array}$ & 14 & \\
\hline
\end{tabular}

Fonte: os autores. 
Quadro 4. Representação das respostas de P3 na Matriz 3×3.

\begin{tabular}{|c|c|c|c|}
\hline $\begin{array}{c}\text { Novas tarefas do } \\
\text { professor } \\
\text { Relações com } \\
\text { o saber }\end{array}$ & $\begin{array}{c}\mathbf{1} \\
\text { Gestão do segmento P-S } \\
\text { (conteúdo) }\end{array}$ & $\begin{array}{c}\mathbf{2} \\
\text { Gestão do segmento P-E } \\
\text { (ensino) }\end{array}$ & $\begin{array}{c}\mathbf{3} \\
\text { Gestão do segmento E-S } \\
\text { (aprendizagem) }\end{array}$ \\
\hline $\begin{array}{c}\text { A } \\
\text { Epistêmica }\end{array}$ & 28 & $19,22,23,26,27,32$ & $24,25,29,31,33$ \\
\hline $\begin{array}{c}\text { B } \\
\text { Pessoal }\end{array}$ & & & 34 \\
\hline $\begin{array}{c}\text { C } \\
\text { Social }\end{array}$ & 20,21 & 30 \\
\hline
\end{tabular}

Fonte: os autores.

Dessa forma, a professora P3 expressou-se em diversas respostas suas reflexões acerca da relação epistêmica com o ensino [19] e [22], revelando até que nunca havia desenvolvido uma prática de ensino pautada no ensino por investigação [26]. Também, ficou clara a relação pessoal que ela atribuiu às suas práticas em sala de aula, pois ao término do desenvolvimento das atividades P3 afirmou estar mais confiante, ver em [20] e [21], visto que vale destacar que P3, no decorrer do desenvolvimento das atividades propostas pelo projeto, solicitou diversas orientações à equipe pedagógica envolvida no processo de formação desses professores.

Observa-se, ainda, que P3 relatou a respeito das relações pessoais e sociais da aprendizagem dos alunos, demonstrando (segundo os critérios da célula de alocação) certo valor atribuído à atividade e ao processo de aprendizagem dos alunos (excertos [34] e [30]).

Os relatos aqui apresentados e as acomodações dessas manifestações na Matriz $3 \times 3$ permitiram-nos evidenciar uma frequência maior na dimensão epistêmica no que diz respeito à relação ao ensino praticado por essas professoras. Dos 34 relatos que trouxemos para análise neste artigo, 16 deles foram alocados na célula 2A, destacando suas preocupações e reflexões com o ensino que praticam considerando as percepções que possuem a respeito do ensino por investigação. De forma secundária, temos também os destaques à célula $3 \mathrm{~A}$, aquela relativa à dimensão epistêmica, porém considerando a aprendizagem dos alunos. Uma possiblidade interpretativa para estas manifestações estarem predominantemente na dimensão epistêmica podem estar relacionadas à natureza das perguntas do questionário aplicado aos professores, pois as perguntas interpelaram os professores a respeito de suas percepções sobre as práticas nas salas de aula e a abordagem ensino por investigação. Mas não necessariamente. Em várias pesquisas temos observado que os professores discorrem e entendem o ambiente da sala de aula de maneiras diferentes: por exemplo, refletem a respeito das atividades pedagógicas na sala de aula, "às vezes expressam sentimentos e emoções pelas situações vividas, outras vezes revelam os valores com que julgam os eventos desse mundo" (Arruda, Passos, 2017 p. 98), nesse caso o mundo escolar.

Diante desses resultados analíticos, tecemos a seguir nossas considerações a respeito do desenvolvimento desta investigação e das conclusões que ela possibilitou evidenciar.

\section{Considerações conclusivas}

De modo geral, buscou-se durante esta investigação identificar as percepções docentes sobre suas práticas pedagógicas por meio do ensino por investigação durante um processo de formação continuada.

A partir das respostas das professoras, que foram coletadas segundo a aplicação de um questionário e tiveram por balizador interpretativo a Matriz $3 \times 3$, foi possível evidenciar que elas possuíam, naquela ocasião, percepções predominantemente epistêmicas em relação ao ensino e à aprendizagem, quando 
observados pelo viés do ensino por investigação nas aulas de Ciências. A Matriz $3 \times 3$ é um instrumento analítico que nos permite evidenciar relações nas dimensões epistêmicas, pessoais e sociais com o conteúdo ou conhecimento, o ensino praticado pelo docente e a aprendizagem dos alunos.

Apesar de termos apresentado neste artigo os dados coletados de somente três professoras, que foram selecionadas por representatividade dos demais professores participantes do projeto de Iniciação Científica desenvolvido pela Secretaria de Educação de um município do estado do Paraná, podemos afirmar que a análise dos dados em sua completude traria resultados bem semelhantes, pelo fato de termos realizado, antes da seleção dessas três depoentes, uma leitura flutuante de todos os retornos, acomodando-os em três conjuntos, dos quais retiramos um representante para aqui discutir.

Esse estudo também nos possibilitou identificar um movimento característico de cada professora, como destacado anteriormente após a apresentação de cada Matriz. Todavia, as maiores discussões e reflexões giraram em torno da dimensão epistêmica, o que nos leva a ressaltar a necessidade de intensificação dos processos formativos continuados para que os professores possam refletir mais sobre os aspectos pessoais e sociais do ensino por investigação. Assim como as demais células da Matriz possam ser povoadas pelas manifestações, o que nos levaria à conclusão de que as percepções a respeito do ensino por investigação estariam próximas de um ideário de relações epistêmica, pessoal e social no que diz respeito ao conhecimento, ao ensino e à aprendizagem. Assumimos este instrumento como balizador das ações em sala de aula e como a possibilidade de um diagnóstico interpretativo dessas ações, pois quanto mais pulverizada mais formativo foi o processo sugestionado por nós.

\section{Referências bibliográficas}

\section{ARCE, A.; SILVA, D.A.S.M.; VAROTTO, M. Ensinando}

Ciências na Educação Infantil. Editora Alínea. Campinas: Brasil. 2011.
ARRUDA, S.M.; PASSOS, M.M. Um instrumento para a análise da relação com o saber em sala de aula. REPPE: Revista do Programa de Pós-Graduação em Ensino, Cornélio Procópio, v. 1, n. 2, pp. 95-115. 2017. https://doi.org/10.3895/ rbect.v10n2.4457

ARRUDA, S. de M.; LIMA, J.P.C.; PASSOS, M.M. Um novo instrumento para a análise da ação do professor em sala de aula. Revista Brasileira de Pesquisa em Educação em Ciências, Belo Horizonte, [s. I.], v. 11, pp. 139-160. 2011.

AZEVEDO, M.C.P.S. de. Ensino por investigação: problematizando as atividades em sala de aula. In: CARVALHO, A.M.P de (Org.). Ensino de ciências: unindo a pesquisa e a prática. Cengage Learning. São Paulo: Brasil. 2006. pp. 19-33.

BACCON, A.L.P. O professor como um lugar: um modelo para análise da regência de classe. 166f. Dissertação (Mestrado em Ensino de Ciências e Educação Matemática) - Universidade Estadual de Londrina, Londrina. 2005.

BARDIN, L. Análise de conteúdo. Edições 70. Lisboa: Brasil. 2011.

BRASIL. Ministério da Educação. Secretaria de Educação Fundamental. Referenciais para a Formação de Professores. Brasília. 1999.

CAMPOS, M.C. da C.; NIGRO, R.G. Didática de ciências: o ensino-aprendizagem como investigação. FTD. São Paulo: Brasil. 1999.

CARVALHO, A.M.P. de. Ensino de Ciências por investigação: condições para implementação em sala de aula. Cengage Learning. São Paulo: Brasil. 2013.

CARVALHO, A.M.P. de; GIL-PÉREZ, D. Formação de Professores de Ciências: tendências e inovaçkões. Cortez. São Paulo: Brasil. 2011.

CHARLOT, B. Da relação com o saber: elementos para uma teoria. Artmed. Porto Alegre: Brasil. 2000.

CHEVALLARD, Y. La transposicion didactica. Aique. Buenos Aires: Argentina. 2005.

CUNHA, A.M. de O.; KRASILCHIK, M. A formação continuada de professores de Ciências: percepções a partir de uma experiência. In: REUNIÃO DA ANPED, 23. Anais [...]. Caxambu. 2000. pp. 1-14. 
GALINDO, C.J.; INFORSATO, E.C. Formação continuada de professores: impasses, contextos e perspectivas. Revista on line de Política e Gestão Educacional, Araraquara, v. 20, n. 03, pp. 463-477. 2016. https://doi.org/10.22633/rpge. v20.n3.9755

GAUTHIER, C. et al. Por uma Teoria da Pedagogia: pesquisas contemporâneas sobre o saber docente. Unijuí. ljuí: Brasil. 2006.

GIL, A.C. Como elaborar projetos de pesquisa. Atlas. São Paulo: Brasil. 2007.

HOUSSAYE, J. Prazer. Currículo sem Fronteiras, [s. I.], v. 7, n. 2, pp. 71-77. 2007.

MIZUKAMI, M.G.N. et al. Formação de Professores: concepções e problemática atual. In: Escola e aprendizagem da docência: processos de investigação e formação. EDUFSCAR. São Carlos: Brasil. 2006. pp. 11-46.

MOITA, M. da C. Percursos de formação e de trans-formação. In: NÓVOA, A. Vidas de professores. 2. ed. Editora Porto. Porto. 1995. pp. 111-140. NIGRO, R.G. Ciências: soluções para dez desafios do professor, $1^{\circ}$ ao $3^{\circ}$ ano do ensino fundamental. Ática Educadores. São Paulo: Brasil. 2011.
PIMENTA, S.G. Formação de Professores - saberes da docência e identidade do professor. In: PIMENTA, S.G. Saberes pedagógicos e atividade docente. Cortez. São Paulo: Brasil. 2012. pp. 15-34.

PIMENTA, S.G.; LIMA, M.S.L. Estágio e docência. Cortez. São Paulo: Brasil. 2004.

SÁ, E.F. Discursos de professores sobre ensino de ciências por investigação. 2009. 203f. Tese (Doutorado em Educação) - Universidade Federal de Minas Gerais, Belo Horizonte. 2009.

SILVA, V.F.; BASTOS, F. Formação de professores de Ciências: reflexões sobre a formação continuada. ALEXANDRIA - Revista de Educação em Ciência e Tecnologia, Florianópolis, v. 5, n. 2, pp. 150-188. 2012.

TARDIF, M. Saberes docentes e formação profissional. 4. ed. Vozes. Petrópolis: Brasil. 2007.

ZÔMPERO, A.F.; LABURÚ, C.E. Atividades investigativas no ensino de Ciências: aspectos históricos e diferentes abordagens. Revista Ensaio, Belo Horizonte [s. I.], v. 13, n. 3, pp.67-80. 2011. https://doi. org/10.1590/1983-21172011130305 